\title{
Equilibrium, Kinetic and Thermodynamic Studies of Biosorption of Methylene Blue on Goethite Modified Baobab Fruit Pod (Adansonia Digitata L.)
}

\author{
*1 ALABI, AH; ${ }^{1,2}$ OLADELE, EO; ${ }^{1}$ ADELEKE, AJO; ${ }^{1}$ ONI, FC; ${ }^{1,3}$ OLANREWAJU, \\ CA
}

\author{
${ }^{*}$ Department of Chemistry, University of Ibadan, Ibadan, Nigeria. \\ ${ }^{2}$ Department of Chemical Sciences, Joseph Ayo Babalola University, Ikeji-Arakeji, Osun State, Nigeria \\ ${ }^{3}$ Department of Chemistry and Biochemistry, Florida International University, Miami FL 33199, USA \\ *Corresponding Author: Email address: helenalabie3@yahoo.com; Tel: +2348028306868
}

\begin{abstract}
Methylene Blue (MB) was adsorbed from aqueous solution using Baobab (Adansonia digitata L.) fruit pod and its goethite modified form. Adsorbents were characterized using Fourier Transform-Infra Red (FTIR) spectroscopy and Scanning Electron Microscopy (SEM). Batch experiments were conducted at room temperature $\left(26.8^{\circ} \mathrm{C}\right)$ and the adsorption data were fitted using Langmuir, Freundlich, Temkin and DubininRadushkevich isotherms. Also, kinetic data was fitted using Pseudo-first order, pseudo-second order, Elovich and intra-particle diffusion models. Goethite modified baobab (GMB) appeared to have a coarse microporous surface with smoother surface and larger pore volumes compared to unmodified baobab (UB). The $-\mathrm{C}=\mathrm{O}$ band was observed at 1631 and $1636 \mathrm{~cm}^{-1}$ for UB and GMB. The -OH band was observed at $3447.00 \mathrm{~cm}^{-1}$ and $3442 \mathrm{~cm}^{-1}$ for UB and GMB respectively. Langmuir model was suitable for describing the adsorption data of UB with $\mathrm{R}^{2}$ of 0.9293 while Temkin model was best for fitting adsorption data of MB on GMB with $\mathrm{R}^{2}$ of 0.9691 . However, maximum adsorption capacity was obtained with Freundlich adsorption isotherm $(15.4253$ and $43.1301 \mathrm{mg} / \mathrm{g}$ for UB and GMB respectively). The maximum biosorption were $8.98 \mathrm{mg} / \mathrm{g}$ and $9.86 \mathrm{mg} / \mathrm{g}$ for UB and GMB respectively at $\mathrm{pH} 10$ Pseudo-second-order kinetic model best fitted the kinetic data with $\mathrm{R}^{2}$ values of 0.9968 and 0.9993 for $\mathrm{UB}$ and GMB, $\Delta \mathrm{H}^{\circ}$ values were $83.123 \mathrm{KJ} / \mathrm{mol}$ and $361.094 \mathrm{KJ} / \mathrm{mol}$ for $\mathrm{UB}$ and $\mathrm{GMB}$, while $\Delta \mathrm{S}^{\circ}$ values were $3.084 \mathrm{~J} / \mathrm{mol} /$ $\mathrm{K}$ and $1.765 \mathrm{~J} / \mathrm{mol} / \mathrm{K}$ for $\mathrm{UB}$ and GMB respectively. GMB adsorbed more of MB than $\mathrm{UB}$ and the process was endothermic.
\end{abstract}

\section{DOI: $\underline{\text { https://dx.doi.org/10.4314/jasem.v24i7.16 }}$}

Copyright: Copyright (C) 2020 Alabi et al. This is an open access article distributed under the Creative Commons Attribution License (CCL), which permits unrestricted use, distribution, and reproduction in any medium, provided the original work is properly cited.

Dates: Received: 16 May 2020; Revised: 29 June 2020; Accepted: 07 July 2020

Keywords: Biosorption, Goethite, Baobab, Isotherms, Methylene blue.

It is well known that the pollution due to synthetic dyes is considered as a serious public concern. The effluents from textile, leather, food processing, cosmetics, paper and dye manufacturing industries are important sources of dye pollution (Bhatnagar and Jain, 2005). An untreated dyes cause chemical and biological changes and lead to a number of environmental and health hazards. Approximately $1000000 \mathrm{~kg} /$ year of dyes are discharged into waste streams by the textile industry (Wong et al., 2004). Many dyes and their breakdown products may be toxic for living organisms (Kannan and Sundaram, 2001). Therefore, decolourization of dyes is important aspect of wastewater treatment before discharge. It is difficult to remove the dyes from the effluent, because dyes are not easily degradable and are generally not removed from wastewater by conventional wastewater systems (Isık and Sponza, 2008). Most of the industrial activities use synthetic dyestuffs in a great number of operations, they consume large quantities of water and they generate considerably large amount of coloured waste water. They can be highly toxic and carcinogenic to human health (Kini et al., 2014). Generally, biological aerobic wastewater systems are not successful for decolourization of majority of dyes.
Therefore, in order to achieve the desired degree of treatment, it is necessary to integrate biological, chemical and physical processes as coagulation, ultrafiltration, electro-chemical adsorption and photooxidation (Kargi and Ozmihc1, 2004). The above mentioned technologies are sometimes inappropriate especially for low-concentration solutions due to economic, technical or environmental reasons. Adsorption is an effective, efficient and economic alternative process for treatment of contaminated wastewater or to remove dyes, pigments and other colourants and also to control the bio-chemical oxygen demand (Kannan and Sundaram, 2001). Adsorption techniques have potential for removing organics from water due to their high efficiency and ability to separate a wide range of chemical compounds (Kumaraswamy et al., 2014). It is by far the most versatile and widely used technique (Dash, 2010) due to its low cost, easy availability, simplicity of design, high efficiency, ease of operation, biodegradability and ability to treat dye in high concentration form (Bulut and Aydın, 2006). Deng et al. (2009) opined that sorption processes are known to have been the most feasible technique for the removal of pollutants from wastewaters nowadays. In recent years, much 
attention has been drawn towards various natural solid materials or biomasses, which are able to remove pollutants from contaminated waste water at low cost. These biomasses can be agricultural waste materials, polysaccharides, industrial waste, biomaterials etc., (Michalak et al., 2013). Activated carbon has been widely used as an adsorbent in wastewater treatment to remove organic and inorganic pollutants. Possessing high specific surface area, activated carbon frequently exhibits high removal efficiency for most dissolved compounds. It has a good capacity for the adsorption of many organic molecules (Kumaraswamy et al., 2014). In spite of this, it suffers from few disadvantages; it is quite expensive (Alam, 2015) and its regeneration produces additional effluent and results in considerable loss (10-15\%) of the adsorbent (Kumaraswamy et al., 2014). Thus, the use of several low cost adsorbents have been studied by many researchers. They have studied the feasibility of using low cost materials such as Malawian baobab (Vunain et al., 2017), Irvingia gabonensis (Inyinbor et. al., 2015), groundnut waste (Etim, 2019), teak leaf, (Gedam et al., 2019), Centella asiatica leaves (Nirmala et al., 2016), African baobab wastes (Tchikuala et al., 2017), Tunisian palm tree date (Guiza et al., 2014), etc. as adsorbents for removal of various dyes from wastewater. These low cost adsorbents have shown effective and economic method for water decontamination (Crini and PierreMarie, 2008). However, the use of non-living biomass has some disadvantages such as: difficulty in separation of biomass from the reaction system, mass loss after regeneration, poor mechanical strength, and small particle size which makes it difficult to use in batch and continuous systems. These problems can be overcome by using a suitable immobilization method (Michalak et al., 2013 and Unuabonah, et al., 2013).

The fruit shell biomass of Adansonia digitata L. was used for the removal of lead (II) and copper (II) from aqueous solution by Chigondo et al. (2013). The nitrilotriacetic acid functionalized Adansonia digitata $L$. was reported as an efficient adsorbent for the removal of lead (II) and copper (II) from aqueous solution by Adewuyi and Pereira, 2016. Zinc (II) ions were adsorbed on magnetite, baobab (Adansonia digitata) and magnetite-baobab composite in the report by Abdus-Salam and Adekola (2018). Kodzwa et al (2015) used the activated carbon obtained from baobab fruit shells for the removal of organic pollutants from water. Misihairabgwi et al (2014) also used the carbons from baobab shells, pigeon pea husks, Moringa oleifera husks and Marula stones for the adsorption of heavy metals. Baobab was used as a precursor to produce carbon for adsorbing diuron, an herbicide that is frequently found in water streams
(Tchikuala et al., 2017). The removal of Methylene Blue from aqueous solution using activated carbon prepared from Malawian baobab was investigated by Vunain and Biswick (2019). There is dearth of information on the removal of Methylene Blue from aqueous solution using either the native Adansonia digitata $\mathrm{L}$. or the goethite modified form. This study aims at finding the suitability of $A$. digitata $L$. and the goethite modified form for the adsorption of Methylene Blue.

\section{MATERIALS AND METHODS}

Materials: Methylene Blue (MB) dye was procured from Trust Chemicallco (Nigeria). The baobab fruit pod sample was obtained from Jos metropolis, in Plateau state. Other reagents used were of analytical reagent grade from BDH limited Poole (England). Deionized water was used in preparing solutions throughout these investigations.

Preparation of the Methylene Blue Solution: The stock solution of $\mathrm{MB}$ dye (chemical formula $\mathrm{C}_{16} \mathrm{H}_{18} \mathrm{ClN}_{3} \mathrm{~S}$, Molecular weight-373.91 g and $\lambda \max 665 \mathrm{~nm}$ ) was prepared by dissolving $1000 \mathrm{mg}$ of $\mathrm{MB}$ in one litre of deionized water. Desired concentrations of the dye solution was obtained from the stock solution through serial dilution.

Preparation of the adsorbents: Preparation of unmodified baobab fruit pod (UB) adsorbent. The UB was prepared according to the method described by Raju et al., (2012). The baobab fruit pods were washed with tap water thrice and once with distilled water to remove any adhering dirt. It was then left to dry in the sun for one week. The dried pods were crushed to powder using a mechanical grinding machine, the grinded pods were then washed with deionized water and dried in the oven at $105{ }^{\circ} \mathrm{C}$. It was then sieved using a $425 \mu \mathrm{m}$ sieve. This was labelled as UB.

Preparation of goethite modified baobab fruit pod (GMB) adsorbent: The procedure of Frini and El Maaoui (1997) was adopted for the synthesis of the goethite modified baobab pod with little modification. The pre-treated biomass was mixed using a using a magnetic stirrer. The goethite modification was carried out by dissolving $60 \mathrm{~g}$ of iron III chloride in $0.1 \mathrm{~L}$ deionized water. $50 \mathrm{~g}$ of the pre-treated baobab fruit pod was mixed with constant stirring using a magnetic stirrer. $2.5 \mathrm{M} \mathrm{NaOH}$ was added slowly until $\mathrm{pH}$ of the suspension was about 12 . The suspension was allowed to age for 24 hours at $60{ }^{\circ} \mathrm{C}$ in an oven. The mixture was filtered using suction pump and washed free of chloride using deionized water. The filtrate was tested for chloride using silver nitrate. After washing, the residue was dried in the oven at $105^{\circ} \mathrm{C}$. The resulting 
adsorbent was named goethite modified baobab fruit pod (GMB).

\section{Adsorbent Characterization}

Scanning Electron Microscope: Surface morphology of the adsorbents before (UB and GMB) and after adsorption (UB/MB and $\mathrm{GMB} / \mathrm{MB}$ ) were determined by using a Scanning Electron Microscope (SEM: model: Phenom World ProX).

Fourier Transform-Infra Red (FT-IR): Functional groups were determined with a Nicolet IR-200 FTIR spectrometer. Discs were prepared by mixing the adsorbent samples with $\mathrm{KBr}$ in a ratio of $1 / 100$ in an agate mortar and the resulting mixture was subsequently pressed at 5 ton for 5 minutes.

pH-point of Zero Charge $\left(\mathrm{pH}_{p z c}\right)$ : The $\mathrm{pH}$ point of zero charge determination $\left(p H_{p z c}\right)$ of the adsorbents was carried out by contacting $0.1 \mathrm{~g}$ of the adsorbent with $50 \mathrm{~cm}^{3}$ of $0.1 \mathrm{M} \mathrm{NaCl}$ whose initial $\mathrm{pH}$ had previously been adjusted between $\mathrm{pH} 2$ and 10 with either $\mathrm{NaOH}$ or $\mathrm{HCl}$. The containers were sealed and placed on a shaker for $24 \mathrm{~h}$ after which the final $\mathrm{pH}$ values were measured. The difference between the initial and final $\mathrm{pH}$ was calculated and plotted against the initial $\mathrm{pH}$. The point of intersection of the resulting curve at which $\Delta p H=0$ gave the point of zero charge $\left(p H_{p z c}\right)$ (Ofudje et al., 2015).

pH of Absorbents: About $0.1 \mathrm{~g}$ of the prepared adsorbent UB was added to $10 \mathrm{~mL}$ of deionized water and shaken for 30 minutes. The suspension was allowed to equilibrate and the $\mathrm{pH}$ was measured thereafter with a $\mathrm{pH}$ meter (model pHS-25) (Inyinbor et al., 2015). This was repeated for the goethite modified baobab.

Batch Adsorption Studies: The adsorption was studied as a function of adsorbent dosage, adsorbent-adsorbate contact time, initial $\mathrm{pH}$ and initial dye concentration. After equilibrium, the contents were filtered and the concentration of the adsorbate in the residual solution $\left(\mathrm{C}_{\mathrm{e}}, \mathrm{mg} / \mathrm{L}\right)$ was determined spectrophotometrically by using a UV-visible spectrophotometer (Spectrumlab 22pc NO: 22PC08476 UV/V spectrophotometer). The amount of $\mathrm{MB}$ adsorbed $\left(q_{e}, \mathrm{mg} / \mathrm{g}\right)$ was determined using equation1.

$$
q_{e}=\left(C_{o}-C_{e}\right) * \frac{V}{m}
$$

Where $\mathrm{C}_{\mathrm{o}}$ and $\mathrm{C}_{\mathrm{e}}$ are the initial and equilibrium concentrations $(\mathrm{mg} / \mathrm{L})$ of $\mathrm{MB}$ in solution, $\mathrm{V}$ is the volume in litres and $\mathrm{m}$ is the mass of the adsorbent in grams.
Effect of adsorbent dosage: A known volume of $\mathrm{MB}$ dye solution $(V=100 \mathrm{~mL})$ at a fixed concentration $\left(C_{o}=20 \mathrm{mg} / \mathrm{L}\right)$ was allowed to be in contact with different amount $(m=0.2-3.0 \mathrm{~g})$ of both adsorbent (UB or GMB) for a fixed interval of time $(t=30 \mathrm{~min})$ until equilibrium was reached and determined.

Effect of initial $\mathrm{pH}$ : The initial $\mathrm{pH}$ of the adsorbate solution was adjusted between 3 and 10 by using $\mathrm{HCl}$ and $\mathrm{NaOH}(0.1 \mathrm{M})$. Other conditions such as adsorbent dose, agitation speed, temperature, contact time and initial adsorbate concentration were maintained at 0.2 g, $150 \mathrm{rpm}, 26 \pm 2{ }^{\circ} \mathrm{C}$ (room temperature), 30 minutes and $20 \mathrm{mg} / \mathrm{L}$, respectively.

Effect of contact time: Adsorption processes were carried out by agitating $0.2 \mathrm{~g}$ of the adsorbent with 100 $\mathrm{mL}$ of $\mathrm{MB}$ solution of desired concentration in different flasks. A shaking speed of $150 \mathrm{rpm}$ was maintained throughout the experiments at room temperature to achieve equilibrium. Samples were withdrawn at different time intervals (30-240 min), filtered and the supernatant was analysed for the change in the concentration of the dye. The quantity of dye adsorbed at a given time $q_{t}(\mathrm{mg} / \mathrm{g})$ was calculated using Equation 2:

$$
q_{t}=\left(C_{i}-C_{t}\right) * \frac{V}{m}
$$

Where $C_{i}$ and $C_{t}$ are the initial concentrations $(\mathrm{mg} / \mathrm{L})$ of $\mathrm{MB}$ in solution and at time t, $V$ is the volume in litres and $m$ is the mass of the adsorbent in grams.

Effect of initial dye concentration: A fixed amount of the adsorbents were mixed with $100 \mathrm{~mL}$ of the adsorbate $(\mathrm{MB})$ solutions with varying concentrations of $20,30,40,50,60,70,80,90$, and $100 \mathrm{mg} / \mathrm{L}$. Taking into consideration the optimum $\mathrm{pH}$, the solutions were shaken for 30 minutes. The residual concentration was determined and resulting data were fitted into different isotherm models.

Adsorption Isotherm: The Langmuir, Freundlich, Temkin and Dubinin-Radushkevich (D-R) isotherm models were used for fitting the adsorption data. These isotherm parameters were calculated and reported accordingly. The best-fit model was selected on the basis of regression coefficient, $R^{2}$ values. The adsorption isotherm models are used for assessing the biosorption capacity of any biosorbent.

Langmuir Isotherm Model: MB adsorption was modelled with the linearized Langmuir adsorption isotherm using equation 3 (Langmuir, 1916):

$$
\frac{1}{q_{e}}=\frac{1}{q_{\max }}+\frac{1}{K_{L} * q_{\max } C_{e}}
$$


Where $C_{e}$ is the concentration of $\mathrm{MB}$ dye in the solution at equilibrium $(\mathrm{mg} / \mathrm{L}), q_{e}$ is the amount of MB dye adsorbed at equilibrium $(\mathrm{mg} / \mathrm{g}), q_{\max }$ is the monolayer adsorption capacity of adsorbent $(\mathrm{mg} / \mathrm{g})$ and $K_{L}$ is the Langmuir adsorption constant $(\mathrm{L} / \mathrm{mg})$. The plot of $1 / q_{e}$ versus $1 / C_{e}$ should give a straight line with a slope of $1 / K_{L} * q_{\max }$ and an intercept of $1 / q_{\max }$. The separation factor, a dimensionless equilibrium parameter $\left(\mathrm{R}_{\mathrm{L}}\right)$ was used to confirm whether the adsorption process was favourable or not. It is expressed by Equation 4:

$$
R_{L}=\frac{1}{1+K_{L} C_{O}}
$$

In this context, lower $R_{L}$ value reflects that adsorption is more favourable. In a deeper explanation, $R_{L}$ value indicates the adsorption nature to be either unfavourable $\left(R_{L}>1\right)$, linear $\left(R_{L}=1\right)$, favourable $(0$ $\left.<R_{L}<1\right)$ or irreversible $\left(R_{L}=0\right)$ (Vučurović et al., 2014).

The Langmuir adsorption isotherm has traditionally been used to quantify and contrast the performance of different biosorbents. It also served to estimate the maximum dye-uptake values which could not be reached by experiments (Padmesh et al., 2008).

Freundlich Isotherm Model: The linearized form of the Freundlich isotherm model is expressed according to equation 5 and was also used to describe the adsorption isotherm for the process.

$$
\ln q_{e}=\ln \mathrm{K}_{F}+\frac{1}{n} \ln C_{e}
$$

Where $q_{e}$ is the amount of $\mathrm{MB}$ dye adsorbed at equilibrium $(\mathrm{mg} / \mathrm{g}), C_{e}$ is the equilibrium concentration of the adsorbate $(\mathrm{mg} / \mathrm{L}) ; \mathrm{K}_{F}$ and $n$ are constants incorporating the factors affecting the adsorption capacity and the degree of non-linearity between the solute concentration in the solution and the amount adsorbed at equilibrium, respectively. The plots of $\ln q_{e}$ against $\ln C_{e}$ should give a linear graph where the values of $n$ and $\mathrm{K}_{F}$ can be obtained from the slope and intercept of the graph, respectively. $K_{F}$ is the Freundlich constant related to overall adsorption capacity $(\mathrm{mg} / \mathrm{g})$; and $1 / n$ is a dimensionless constant related to the intensity of adsorption, or the heterogeneity factor and is not restricted to the formation of the monolayer.

Temkin Isotherm Model: Then Temkin model was used to describe the adsorption isotherm of the process using the following Equation 6 (Tempkin and Pyzhev,
1940) which contains a factor that takes into account the adsorbent-adsorbate interactions.

$$
\mathrm{q}_{e}=\beta \ln K_{T}+\beta \ln C_{e}
$$

Where $\mathrm{q}_{e}$ is the amount of adsorbate adsorbed at equilibrium $(\mathrm{mg} / \mathrm{g}), C_{e}$ is equilibrium concentration of adsorbate $(\mathrm{mg} / \mathrm{L}) . \beta(\mathrm{J} / \mathrm{mol})$ is a constant related to the heat of absorption given as

$$
\beta=\frac{R T}{b_{T}}
$$

$b_{T}$ is the Temkin constant $(\mathrm{J} / \mathrm{mol}), T$ is the absolute temperature $(\mathrm{K}), R$ is the gas constant $\left(8.314 \mathrm{~J} \mathrm{~mol}^{-1}\right.$ $\mathrm{K})$ and $\mathrm{K}_{T}$ is the Temkin isotherm constant $(\mathrm{L} / \mathrm{g})$. $\frac{R T}{b_{T}}$ and $\mathrm{K}_{T}$ can be calculated from the slope $\left(\mathrm{K}_{T}\right)$ and intercept $\left(\frac{R T}{b_{T}} \ln \mathrm{K}_{T}\right)$ of the plot of $q_{e}$ against $\ln C_{e}$ which will result to a straight line.

Dubinin-Radushkevich Isotherm Model: The DubininRadushkevich (DR) model is a more general model that does not assume a homogenous surface or constant adsorption potential. The DR model gives information about the sorption mechanism, whether physical or chemical adsorption (Dubinin, 1960) and it is expressed linearly by Equation 8:

$$
\ln \left(q_{e}\right)=\ln \left(q_{s}\right)-K_{e d} \varepsilon^{2}
$$

Where $q_{e}$ is the amount of MB ions adsorbed per unit mass of adsorbent $(\mathrm{mg} / \mathrm{g}), q_{s}$ is the maximum sorption capacity, $K_{e d}$ is the activity coefficient related to the mean sorption energy $E(\mathrm{~kJ} / \mathrm{mol})$ and $\varepsilon$ is the Polanyi potential. $\varepsilon$ is expressed by Equation 9:

$$
\varepsilon=R T * \ln \left[1+\frac{1}{C_{e}}\right]
$$

The mean free energy, $E$ per molecule of adsorbate (for removing a molecule from its location in the sorption space to the infinity) can be computed by the relationship in Equation 10:

$$
E=\left[\frac{1}{\sqrt{2 B_{D R}}}\right]
$$

Adsorption Kinetics: Adsorption data were tested by using the pseudo-first-order, pseudo-second-order, Elovich and the intra-particle diffusion models.

Pseudo-first-order Kinetics Model: The pseudo-firstorder kinetics model of Lagergren is given by Equation 11-13 (Ho and McKay, 1998).

$\log \left(q_{e}-q_{t}\right)=\log \left(q_{e}\right)-\frac{K_{1}}{2.303} t$ 
Then after arrangement we have the integrated form to be;

$\ln \left(q_{e}-q_{t}\right)=\ln \left(q_{e}\right)-K_{1} t$

A plot of $\ln \left(q_{e}-q_{t}\right)$ against $t$ should give a linear relationship with the slope $K_{1}$ and intercept of $\ln \left(q_{e}\right)$, where $K_{1}$ is the PFOM rate constant $(1 / \mathrm{min})$ (Padmesh et al., 2008).

The Lagergren rate equation may have been the first rate equation for the sorption in liquid/solid systems based on solid capacity. It can also be expressed as

$$
\frac{d q_{t}}{d t}=K_{1}\left(q_{e}-q_{t}\right)
$$

Where $q_{e}$ and $q_{t}$ are the quantity absorbed at equilibrium and at time $t$, respectively $(\mathrm{mg} / \mathrm{g})$, and $K_{1}$ is the rate constant for the pseudo-first-order sorption $\left(\min ^{-1}\right)$. A plot of $\ln \left(q_{e}-q_{t}\right)$ against $\mathrm{t}$ for $\mathrm{UB}$ and GMB at different concentrations should give linear graphs with negative slopes from which $K_{1}$ and calculated quantity adsorbed at equilibrium $\left(q_{e}\right.$, cal) can be obtained from the slope and intercept, respectively.

Pseudo-second-order Kinetics Model: The pseudosecond-order kinetics model is given by Equation 14 (Uddin et al., 2007):

$$
\frac{d q_{t}}{d t}=K_{2}\left(q_{e}-q\right)^{2}
$$

Where $K_{2}$ is the rate constant of pseudo-second order sorption $(\mathrm{mg} / \mathrm{g} / \mathrm{min}) q_{e}$ and $q_{t}$ are the amount adsorbed at equilibrium and at time $t$ respectively.

The linear form of Equation 14 becomes:

$$
\frac{t}{q_{t}}=\frac{1}{K_{2} q_{e}^{2}}+\frac{t}{q_{e}}
$$

A plot of $t / q_{t}$ against $t$ should give a linear relationship. The $q_{e}$ and $K_{2}$ can be determined from the slope and intercept of the plot (Uddin et al., 2007). $\mathrm{K}_{2}$ is the rate constant of pseudo-second-order-model (PSOM) sorption $\left(\mathrm{g} \mathrm{mg}^{-1} \mathrm{~min}^{-1}\right)$.

The initial adsorption rate, $h(\mathrm{mg} / \mathrm{g} / \mathrm{min})$ is expressed by the following Equation 16:

$$
h=K_{2} q_{e}^{2}
$$

$\mathrm{K}_{2} \mathrm{qe}^{2}$ is the initial rate constant (represented by $\mathrm{h}, \mathrm{mg}$ $\left.\mathrm{g}^{-1} \min ^{-1}\right)$. The values of $\mathrm{q}_{\mathrm{e}}$ and $\mathrm{K}_{2}$ can be determined from the slope and intercept of the plot, respectively (Rezaei, 2016).

Elovich Model: The Elovich equation is generally expressed as

$$
\frac{d q_{t}}{d t}=\alpha \exp ^{(-\beta q t)}
$$

Where $q_{t}$ the amount adsorbed at time $t, \alpha$ and $\beta$ are constants during any one experiment. The constant $\alpha$ can be regarded as initial rate since $\frac{d q_{t}}{d t} \rightarrow \alpha$ as $q_{t} \rightarrow$ 0 , i.e., a rapid adsorption not governed by the exponential law (Low, 1960).

Assuming that $q_{t}=0$ at $t=0$, the integrated form of Equation 17 becomes

$$
q_{t}=(1 / \beta) \ln (1+\alpha \beta t)
$$

To simplify the Elovich equation, we assume $\alpha \beta t>>$ $l$, Equation 18 thus can be simplified as

$$
q_{t}=\left(\frac{1}{\beta}\right) \ln (\alpha \beta)+\left(\frac{1}{\beta}\right) \ln t
$$

Thus, a plot of $q_{t}$ vs. $\ln t$ should give a linear relationship with the slope of $(1 / \beta)$ and intercept of $(1 / \beta) \ln (\alpha \beta)$ (Chien and Clayton, 1955).

Intra-particle diffusion model: According to Weber and Morris, (1963) kinetic model should identify if the sorption process is intra-particle diffusion mechanism or not. It has been shown to be an important factor in determining the attainment of equilibrium in immobilized biosorbent. The intra-particle diffusion model equation is given as

$$
q_{t}=k_{i d} t^{1 / 2}+c
$$

Where $q_{t}(\mathrm{mg} / \mathrm{g})$ is the amount of MB dyes adsorbed at time $t$. The $k_{i d}\left(\mathrm{mg} / \mathrm{g} / \mathrm{min}^{1 / 2}\right)$ is the rate constant for intra particle diffusion. The value of $\mathrm{C}$ explains the thickness of the boundary layer, the larger the intercept the greater the boundary layer effect. $k_{i d}$ values can be calculated from the slope of the plot of $q_{t}$ against $t^{1 / 2}$ which gives a multi-linear form for biosorption of adsorbate. The initial portion of the curve is reflecting the boundary layer diffusion effect and final linear part of the curve show the effect of intra-particle diffusion. The larger the intercept, the greater the contribution of the surface sorption in the rate controlling step i.e. the value of $\mathrm{C}$ gives an idea about the thickness of boundary layer. If the plot passes through the origin, then intra-particle diffusion is the rate-determining step (Park et al., 2010) (Inyinbor et al., 2015). 
Validity of Models: Inyinbor et al., (2015) used a normalized standard deviation, $\Delta q_{e}(\%)$ which is expressed by Equation 21 to verify the kinetic models used to describe the adsorption process.

$$
\Delta q_{e}(\%)=100 \sqrt{\left[\frac{\left(q_{e, e x p}-q_{e, c a l}\right) / q_{e, e x p}}{N-1}\right]}
$$

Where $N$ is the number of data points, and $q_{e, \exp }$ and $q_{e, c a l}(\mathrm{mg} / \mathrm{g})$ are the experimental and calculated values of the quantity adsorbed at equilibrium, respectively. A lower value of $\Delta q_{e}$ indicates a good fit between the experimental and calculated data.

Thermodynamic Parameters: The thermodynamics of the adsorption is determined by using the following equation:

$$
\ln \left(\mathrm{K}_{\mathrm{L}}\right)=\Delta \mathrm{S}^{\mathrm{o}} / \mathrm{R}-\Delta \mathrm{H}^{\mathrm{o}} / \mathrm{RT}
$$

Where $\mathrm{K}_{\mathrm{L}}$ is the Langmuir constant $(\mathrm{L} / \mathrm{mol}) ; \mathrm{R}$ and $\mathrm{T}$ represent the universal gas constant $(8.314 \mathrm{~J} / \mathrm{mol} / \mathrm{K})$ and the system temperature $(\mathrm{K})$ respectively. $\Delta \mathrm{S}^{\circ}$ and $\Delta \mathrm{H}^{\mathrm{o}}$ are determined from the intercept and slope of the Van't Hoff plots of $\ln \left(K_{L}\right)$ versus $1 / T$.

\section{RESULTS AND DISCUSSION}

Characterization of adsorbents: The morphological features and surface characteristics of adsorbent materials are widely studied by using scanning electron microscope (SEM). The SEM image of adsorbent before adsorption are shown in Figures 1(a) for UB and 1(b) for GMB. Figure 2 shows the SEM images of the adsorbents after adsorption (i.e. UB/MB is shown in Figure 2(a) and GMB/MB is shown in Figure 2(b) with different magnifications of $500 x$, 1000x 1500x and 2000x of each of the adsorbent respectively. The SEM image shown in Figure 1(a and b) appeared to have irregular and porous surface structure, which is a requirement for a potential adsorbent as clearly seen in the image. The porous structure indicates that physical adsorption plays a major role in the removal of adsorbate from solution (Vafakhah et al., 2014).

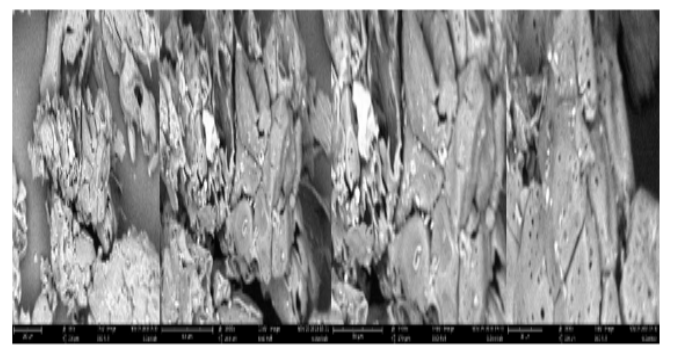

Fig 1(a). The SEM image of the Unmodified Baobab Fruit Pod (UB)

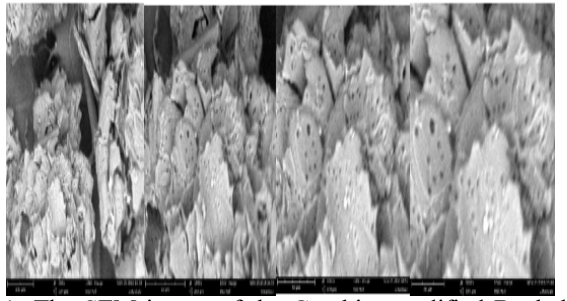

Fig 1(b). The SEM image of the Goethite modified Baobab Fruit Pod (GMB)

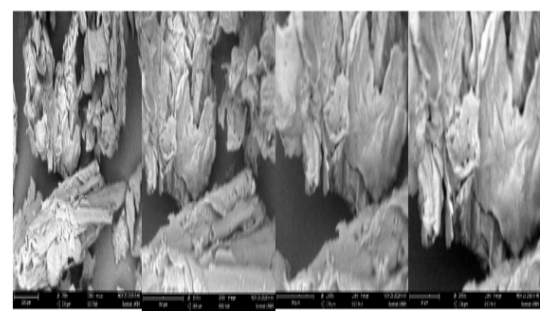

Fig 2(a). The SEM image of the UB after adsorption with Methylene blue (UB/MB)

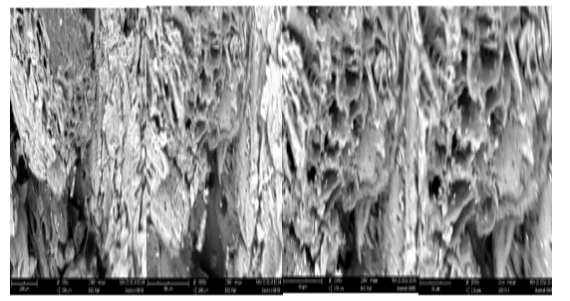

Fig 2(b). The SEM image of the GMB after adsorption with Methylene blue (GMB/MB)

Functional Groups: The FTIR spectra obtained for the two materials before and after sorption are presented in Figure 3 and 4. UB shows an absorption band at $1113.00 \mathrm{~cm}^{-1}$ which corresponds to $\mathrm{C}-\mathrm{O}$ bands of ether or carboxylic acid (which is in the range of 1300 to $\left.1000 \mathrm{~cm}^{-1}\right), 1436.00 \mathrm{~cm}^{-1}$ were assigned to $\mathrm{C}-\mathrm{H}$ bend vibration and the peaks around $1440 \mathrm{~cm}^{-1}$ indicates the presence of $\mathrm{CH}_{2}$ and $\mathrm{CH}_{3}$ groups while peaks around $1420 \mathrm{~cm}^{-1}$ can be attributed to the aromatic $\mathrm{CH}$ and carboxyl-carbonate structures), $1631.00 \mathrm{~cm}^{-1}$ indicates asymmetric $\mathrm{C}=\mathrm{O}$ of ester or non-conjugated $\mathrm{C}=\mathrm{C}$ stretching vibration which is known to show peaks near $1620 \mathrm{~cm}^{-1}$ to $1680 \mathrm{~cm}^{-1}$, and $3447.00 \mathrm{~cm}^{-1}$ (-OH) (Figure 3a). However, after sorption there was a shift, disappearance, and appearance of a new peak and intensity decrease in the bands. The disappearance of$\mathrm{OH}$ stretch and $\mathrm{C}-\mathrm{H}$ bend vibrations, appearance of $1744.00 \mathrm{~cm}^{-1}$ of carbonyl stretching $(\mathrm{C}=\mathrm{O})$ of carboxylic acid and the shift to the peaks $1656.00 \mathrm{~cm}^{-}$ ${ }^{1}$ of asymmetric $\mathrm{C}=\mathrm{O}$ of ester and $1160.33 \mathrm{~cm}^{-1}$ of $\mathrm{C}-$ $\mathrm{O}$ bands of ether or carboxylic acid respectively (Figure $3 \mathrm{~b}$ ). For GMB, the $-\mathrm{OH}$ band appeared at $3442.00 \mathrm{~cm}^{-1}$. Other characteristic functional group bands such as $1113.00 \mathrm{~cm}^{-1}(\mathrm{C}-\mathrm{O}$ bands of ether or carboxylic acid), $1636.42 \mathrm{~cm}^{-1}$ (asymmetric $\mathrm{C}=\mathrm{O}$ of 
ester or non-conjugated $\mathrm{C}=\mathrm{C}$ stretching vibration which is known to show peaks near $1620 \mathrm{~cm}^{-1}$ to 1680 $\mathrm{cm}^{-1}$ ) were also present (Figure 4a). After sorption, there was a shift in the $-\mathrm{OH}$ and $\mathrm{C}=\mathrm{O}$ of ester, $\mathrm{OH}$ bands shifted to $3408.00 \mathrm{~cm}^{-1}, \mathrm{C}=\mathrm{O}$ bands to 1629.0 $\mathrm{cm}^{-1}$, and $\mathrm{C}-\mathrm{O}$ bands shifted to $1043.78 \mathrm{~cm}^{-1}$. A new peak of $1418 \mathrm{~cm}^{-1}$ can be attributed to the aromatic $\mathrm{CH}$ (Figure $4 \mathrm{~b}$ ). The SEM image of UB shown in Figure 1(a) indicated to have an uneven cavities and fewer smaller porous volume. GMB SEM image in Figure 1(b) appeared to have a coarse microporous surface with smoother surface area and larger pore volume compared to UB. After adsorption of $\mathrm{MB}$, the pores earlier observed on the surface of UB and GMB were covered by the MB molecules as shown in Figure 2(a) and $2 \mathrm{~b}$ respectively.

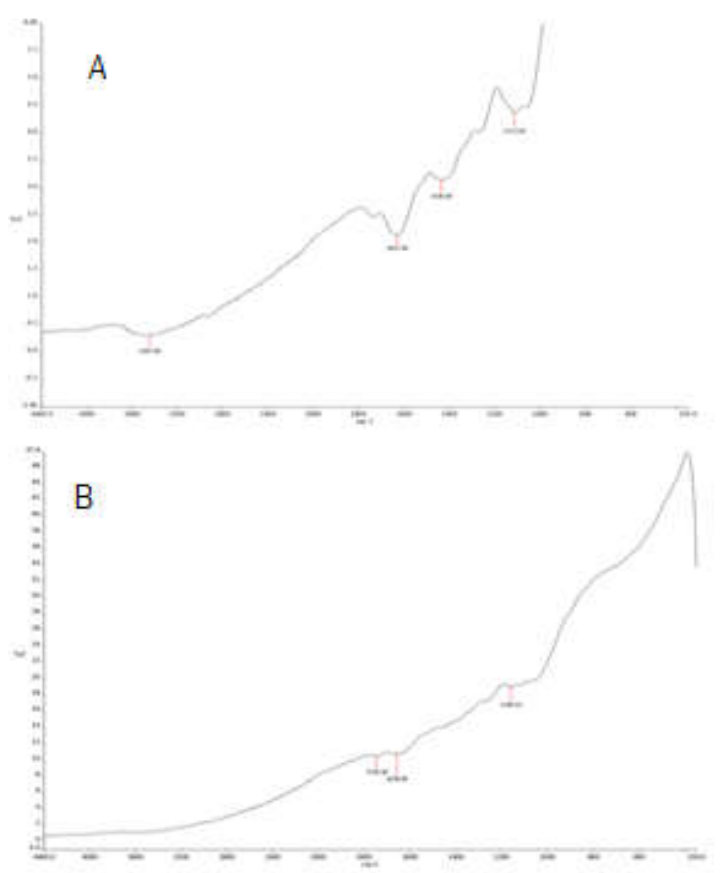

Fig 3: FTIR spectrum for UB (a) and MB/UB (b)

Table 2: Point of zero charge and $\mathrm{pH}$ for the two adsorbents

\begin{tabular}{lll}
\hline Adsorbents & pH at point of Zero & pH \\
\hline Unmodified baobab (UB) & 7.50 & 8.35 \\
Goethite-modified (GMB) & 6.00 & 9.29 \\
\hline
\end{tabular}

Batch Adsorption Studies: Effect of Adsorbent Dosage on the Uptake of MB onto UB and GMB. The adsorption capacity for UB and GMB was observed to decrease (from $9.27 \mathrm{mg} / \mathrm{g}$ to $0.63 \mathrm{mg} / \mathrm{g}$ and $9.82 \mathrm{mg} / \mathrm{g}$ to $0.63 \mathrm{mg} / \mathrm{g}$ respectively) as the sorbent dosage increases over the range of sorbent dosage studied $(0.2$ g-3.0 g) as shown in Figure 5(a). However, $0.2 \mathrm{~g}$ was maintained for the other experiment as the equilibrium dosage.
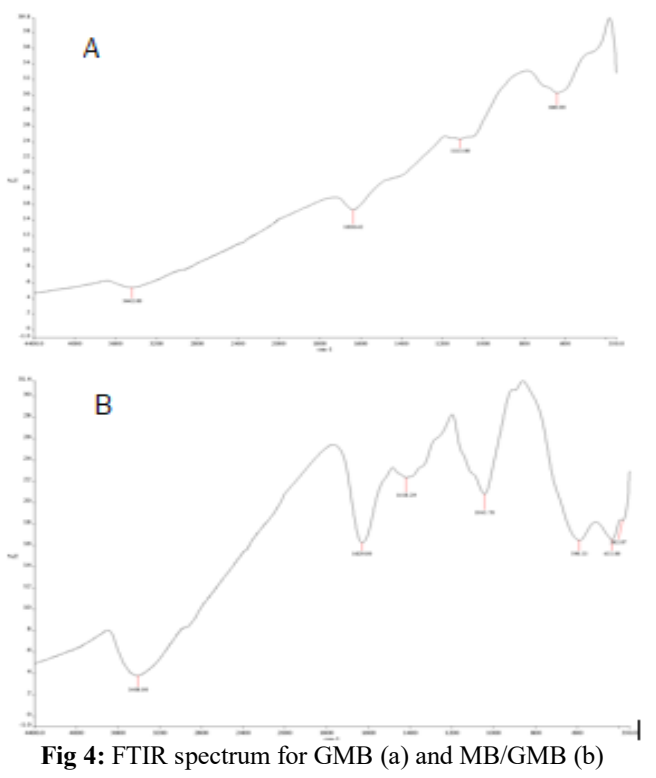

Effect of Solution $p H$ on the Uptake of $M B$ onto $U B$ and $G M B$ : The efficiency of adsorption depends on the solution $\mathrm{pH}$ because variation in $\mathrm{pH}$ leads to the variation in the degree of ionization of the adsorptive molecule and the surface properties of adsorbent (Milani et al., 1992). The effects of solution $\mathrm{pH}$ on the adsorption of $\mathrm{MB}$ onto $\mathrm{UB}$ and GMB were investigated within the $\mathrm{pH}$ range of $3-10$. The $\mathrm{pH}$ of the solution was adjusted by using either $0.1 \mathrm{M} \mathrm{HCl}$ or $0.1 \mathrm{M} \mathrm{NaOH}$ and the results are presented in Figure 5(b). Maximum adsorption capacity was recorded at $\mathrm{pH} 10$, where the uptake of MB onto UB and GMB were $9.68 \mathrm{mg} / \mathrm{g}$ and $9.86 \mathrm{mg} / \mathrm{g}$ respectively, while minimum adsorption capacity occurred at $\mathrm{pH} 3$ with $8.99 \mathrm{mg} / \mathrm{g}$ and $9.76 \mathrm{mg} / \mathrm{g}$ for UB and GMB respectively. The high biosorption capacity and percentage of $\mathrm{MB}$ dye removal at high $\mathrm{pH}$ can be attributed to the presence of less hydrogen ion $\mathrm{H}^{+}$ competing for sorption sites on the negatively charged surface adsorbents due to more availability of $\mathrm{OH}^{-}$on the adsorbent surface. High $\mathrm{pH}$ leads to a decrease in $\mathrm{H}^{+}$ion concentration in the system, and the surface of the adsorbents acquires more $\mathrm{OH}^{-}$groups, hence more amount of cationic $\mathrm{MB}$ dye adsorption takes place as $\mathrm{pH}$ increases. Therefore, increase in $\mathrm{pH}$ of the $\mathrm{MB}$ dye solution give rise to electrostatic interaction between both negatively charged adsorbent surface and cationic $\mathrm{MB}$ dye solution to form complexes (i.e.) less $\mathrm{H}^{+}$ions and more $\mathrm{OH}^{-}$came into solution which gives increase of the biosorption capacity $q_{e}$ (Milani et al., 1992). Similar trend was reported for adsorption of MB onto rice husk (Vadivelan and Kumar, 2005), palm kernel shell activated carbon (Jumasiah et al., 2005) and wheat shells (Bulut and Aydın, 2006). 

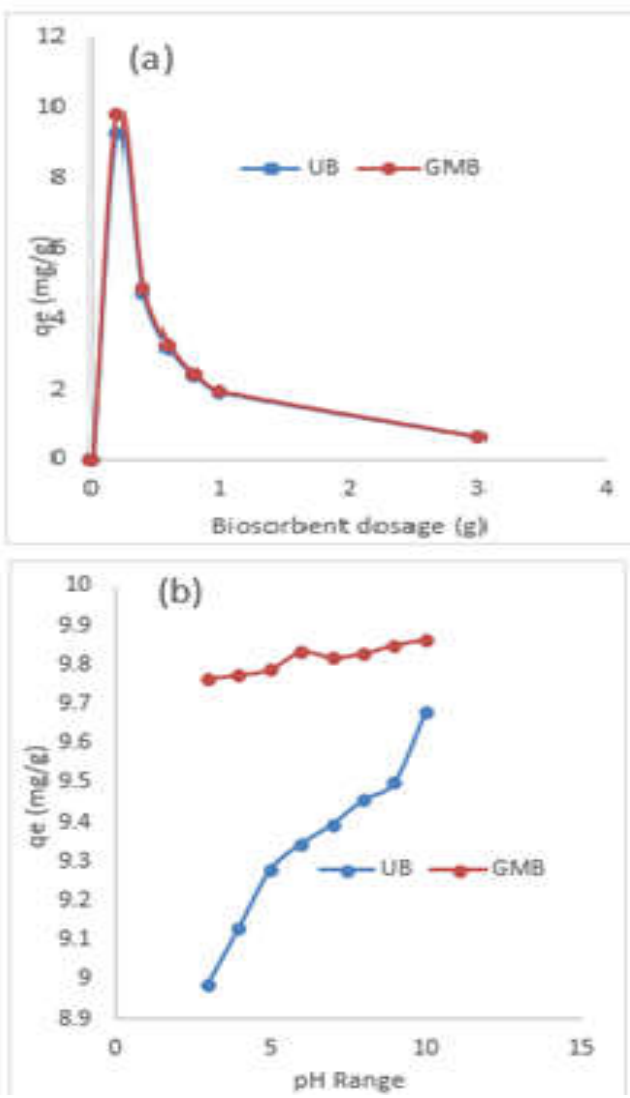

Fig 5: Effect of adsorbent dosage (a) and $\mathrm{pH}(\mathrm{b})$ on the biosorption of $\mathrm{MB}$ on unmodified baobab fruit pod (UB) and goethite modified baobab fruit pod (GMB). Initial MB concentration: $20.0 \mathrm{mg} / \mathrm{L}$, biosorbent dosage $0.2 \mathrm{~g}$. Agitation speed: $150.0 \mathrm{rpm}$. Contact time of 30.0 minutes and temperature $26.2^{\circ} \mathrm{C}$.

Effect of Initial Dye Concentration on the Uptake of $M B$ onto $U B$ and $G M B$ : Figures 6 a depicts the percentage removal of the adsorbate-adsorbent interactions as a function of concentration (20-100 $\mathrm{mg} / \mathrm{L})$. The uptake of $\mathrm{MB}$ by $\mathrm{UB}$ and $\mathrm{GMB}$ was observed to be rapid and the quantity adsorbed $\left(q_{e}\right)$ at a fixed time (30 $\mathrm{min})$ increased with increase in initial dye concentration while the maximum percentage removal $(97.6 \%)$ occurred at initial concentration of $80 \mathrm{mg} / \mathrm{L}$ for $\mathrm{UB}$ and $98.95 \%$ at $50 \mathrm{mg} / \mathrm{L}$ for GMB.

Effect of Contact time: The effect of contact time on the adsorption of MB dyes was investigated at $20 \mathrm{mg} / \mathrm{L}$ initial dye concentration onto both adsorbent (UB and GMB), and results is presented in Figure 7. It was observed that the amount of $\mathrm{MB}$, that is milligrams of adsorbate per gram of adsorbent (UB and GMB), increases with increasing contact time at constant initial dye concentration $20 \mathrm{mg} / \mathrm{L}$ for UB from 9.53 $\mathrm{mg} / \mathrm{g}$ at 30 minutes to $9.84 \mathrm{mg} / \mathrm{g}$ at 150 minutes and decrease to $9.20 \mathrm{mg} / \mathrm{g}$ at 240 minutes. So, equilibrium is attained within 150 minutes and for GMB from 9.83 $\mathrm{mg} / \mathrm{g}$ at 30 minutes to $9.89 \mathrm{mg} / \mathrm{g}$ at 120 minutes and decrease to $9.52 \mathrm{mg} / \mathrm{g}$ at 180 minutes and increases again to $9.78 \mathrm{mg} / \mathrm{g}$ at 240 minutes. So, equilibrium is attained within 150 minutes for UB and 120 minutes for GMB. Basically, from both Figures 7, the percentage adsorbed increases and the amount of adsorption increases with increasing contact time up to equilibrium time. This is because the initial dye concentration provides the driving force to overcome the resistance to the mass transfer of dye between the aqueous liquid and the solid phase (Kumar et al., 2010). For constant dosage of adsorbent, at constant initial dye concentration, the available adsorption sites of adsorbent become fewer, and hence, equilibrium is attained at the maximum biosorption capacity at a particular time $q_{t}$.

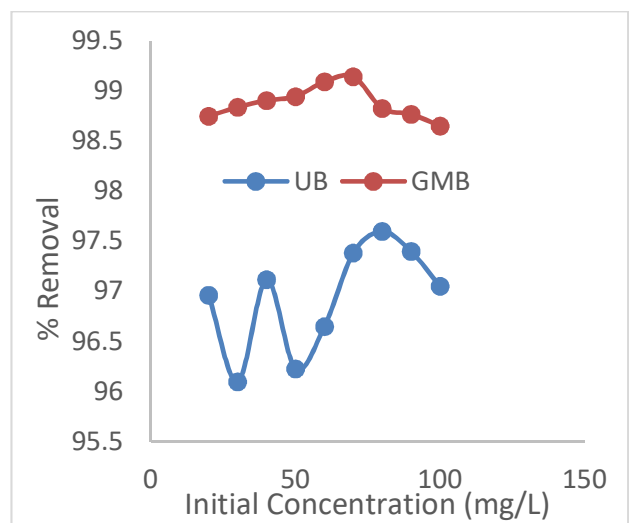

Fig 6: Effect of initial concentration on the biosorption of $\mathrm{MB}$ on $\mathrm{UB}$ and $\mathrm{GMB}$ as function of percentage removal. Biosorbent dose: $0.2 \mathrm{~g}$ of both adsorbent, agitation speed: $150.0 \mathrm{rpm}$, contact time: 30 minutes, $\mathrm{pH} 10$ and temperature $26.2^{\circ} \mathrm{C}$.

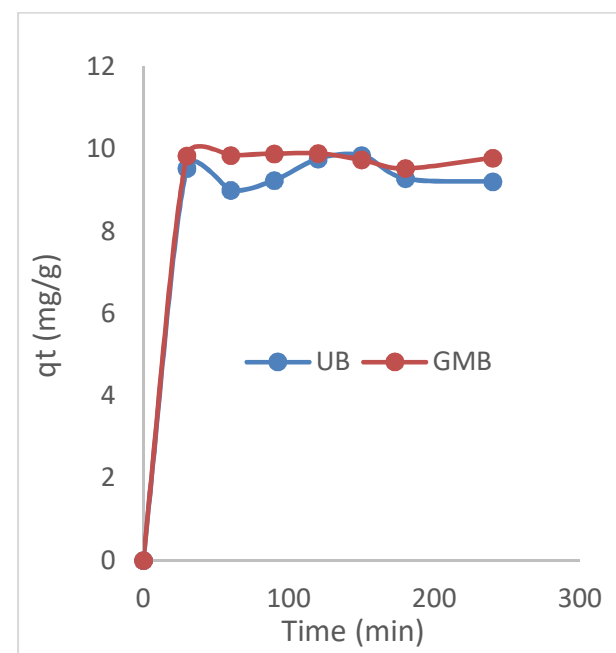

Fig 7: Effect of contact time on the biosorption of $\mathrm{MB}$ on unmodified baobab fruit pod (UB) and goethite modified baobab fruit pod (GMB). Biosorbent dose: $0.2 \mathrm{~g}$ of both adsorbent, agitation speed: $150.0 \mathrm{rpm}$, contact time range of 30-240 minutes and temperature: $26.2{ }^{\circ} \mathrm{C}$. 


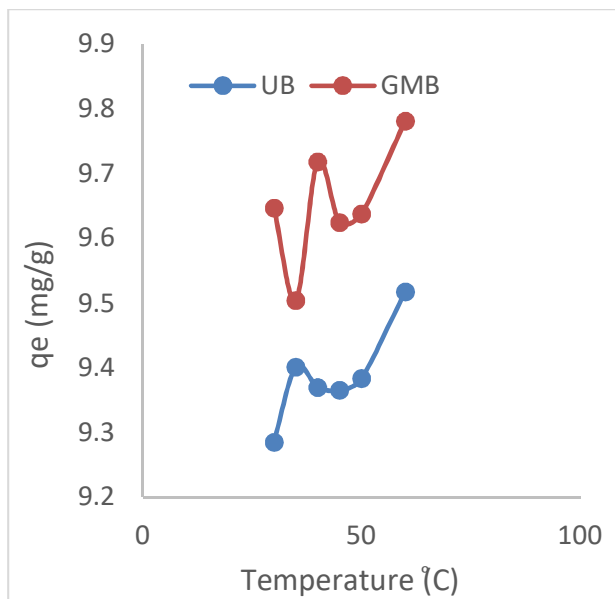

Fig 8: Effect of and effect of temperature (b) on the biosorption of MB on unmodified baobab fruit pod (UB) and goethite modified baobab fruit pod (GMB). Biosorbent dose: $0.2 \mathrm{~g}$ of both adsorbent, agitation speed: $150.0 \mathrm{rpm}$, contact time 30 minutes and temperature: $27-60{ }^{\circ} \mathrm{C}$.

Effect of Temperature: Temperature is one of the factors that may influence biosorption process. Influence of temperature within range $30-60{ }^{\circ} \mathrm{C}$ for the initial concentrations of dye: $20 \mathrm{mg} \mathrm{L}^{-1}, 30$ minutes shake and working $\mathrm{pH}$ of 10 for both adsorbent Figure 8 was investigated. Temperature increase from 30 to $60{ }^{\circ} \mathrm{C}$ caused $\mathrm{MB}$ to show an increase in sorption capacity $(9.2851 \mathrm{mg} / \mathrm{g}$ to $9.5174 \mathrm{mg} / \mathrm{g}$ for $\mathrm{UB} / \mathrm{MB}$ and $9.647 \mathrm{mg} / \mathrm{g}$ to $9.7811 \mathrm{mg} / \mathrm{g}$ for $\mathrm{GMB} / \mathrm{MB})$. So it can be concluded that sorption process was endothermic in nature. Biosorption rate depends on temperature according to Arrhenius equation:

$$
K_{2}=A_{0} \exp \left[E_{a} /(R T)\right]
$$

Where $K_{2}$ is pseudo-second-order of biosorption ( $\mathrm{g}$ $\left.\mathrm{mg}^{-1} \mathrm{~min}^{-1}\right), A_{0}$ is the constant called the frequency factor $\left(\mathrm{g} \mathrm{mg}^{-1} \mathrm{~min}^{-1}\right), \mathrm{R}$ is the universal gas constant (8.314 $\mathrm{J} \mathrm{mol}^{-1} \mathrm{~K}^{-1}$ ), and $\mathrm{T}$ is the temperature of solution in kelvin $(K)$. Graph of relationship of natural logarithm of $k_{2}\left(\ln K_{2}\right)$ against $1 / T$ is a straight line, from its equation the activation energy $\left(E_{a}\right)$ may be determined. Magnitude of activation energy indicates adsorption mechanism, for chemical adsorption it is always higher than 4-6 kJ mol${ }^{-1}$, physical adsorption is characterized by lower activation energy (below 4 $\mathrm{kJ} \mathrm{mol}^{-1}$ ).

Biosorption Isotherms: The biosorption capacity of the two adsorbents were carried out for $\mathrm{MB}$, the equilibrium isotherms are characterized by certain constant values which expresses the surface properties and affinity of the biosorbent. These isotherms can also be used to explain the adsorption mechanism either by monolayer or multi-layer.

Langmuir Isotherm: Langmuir Isotherm corresponds to monolayer coverage of the biosorbent surface without the lateral interaction. Table 3 shows Langmuir isotherm constant for the two adsorbents used to adsorbed $\mathrm{MB}$ and $\mathrm{R}^{2}$ values obtained were 0.9293 for UB and 0.9564 for GMB, this indicates a satisfactory biosorption process as depicted in Figure 9 but the $R_{L}$ values of $-2.63-(1.38)$ and -0.057 - (0.373 ) for $\mathrm{UB}$ and $\mathrm{GMB}$ respectively depicts an unfavourable biosorption process. So it can be concluded that Langmuir Isotherm fairly describe the adsorption of MB on both adsorbent. The $q_{\max }$ is the $q_{e}$ for a complete monolayer $(\mathrm{mg} / \mathrm{g})$. The $K_{L}$ in the Langmuir model measures the affinity of the adsorbent for the solute. A higher value of $K_{L}$ means a higher adsorption level at low solution concentration and vice-versa (Xiong and Mahmood, 2010). Low $K_{L}$ values in Table 3 depict a little affinity of the adsorbent for the cationic dye.

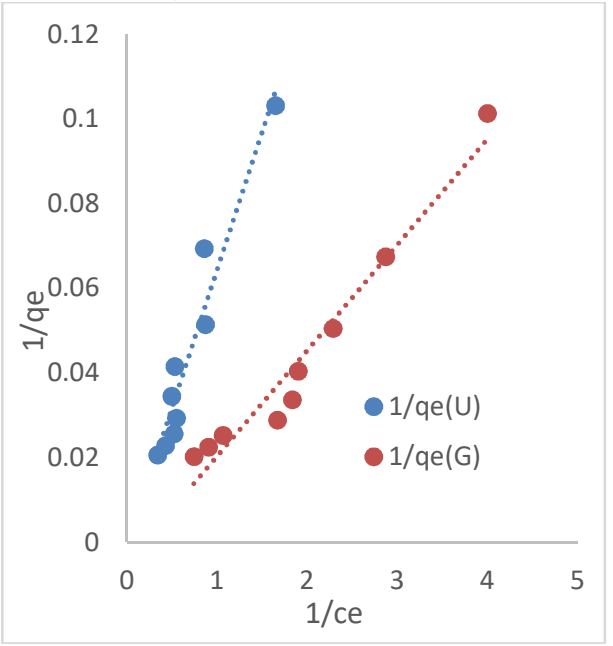

Fig 9: The linearized Langmuir biosorption isotherm of $M B$ on UB and GMB

Freundlich Isotherm: The Freundlich isotherm is empirically derived and is described based on two factors namely, the energetic surface heterogeneity and lateral interaction between the adsorbed molecules. These two factors are commonly observed with precipitation process (Eberhardt, et al., 2006). The data obtained from the MB adsorption on the two adsorbents were fitted into Freundlich isotherm. Table 3 gives a summary of Freundlich constants values and the regression values. The regression values of 0.9026 for $\mathrm{UB}$ and 0.9245 for GMB were obtained for MB, these high values portray that equilibrium data from the two adsorbents do agree with this model. Constant 
$n$ in Table 3 is a measure of deviation from linearity, when $n$ is greater than 1 , the biosorption bond becomes weak and the value of sorption capacity changes significantly with small changes in concentration (Akbal, 2005). Thus $n$ values for MB adsorption on $\mathrm{UB}$ and GMB are 0.923 and 1.065 respectively. However, when $\mathrm{n}$ value is less than 1 , increased adsorption affects the sorbent in a manner that increases the sorption capacity, such as forming new sites (Carvalho et al., 2011).

Temkin Isotherm: The data obtained were also fitted into Temkin Isotherm and results obtained are represented in Table 3. The heat of biosorption $b_{T}$ for the MB, 1638.4308 and $4325.1964 \mathrm{KJ} / \mathrm{mol}$. The $\mathrm{R}^{2}$ value for the adsorbate adsorption on UB and GMB are shown in Table 3.

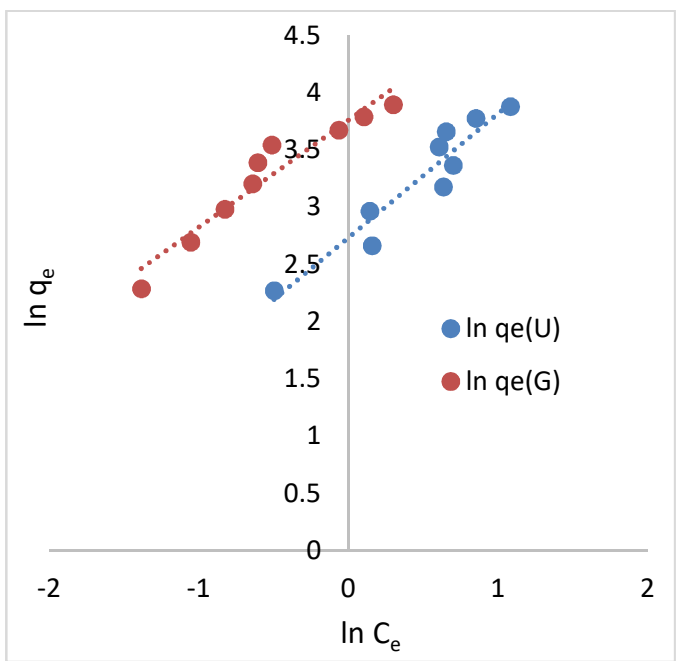

Fig 11: The linearized Freundlich biosorption isotherm of $M B$ on UB and GMB

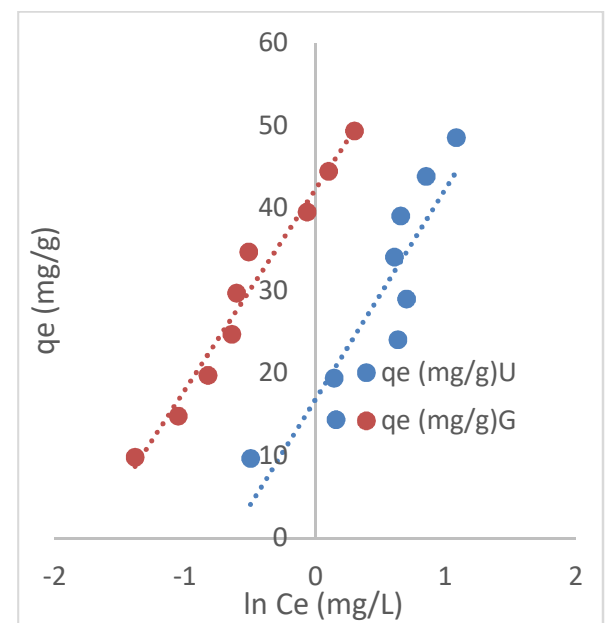

Fig 11: The linearized Temkin biosorption isotherm of $M B$ on $U B$ and GMB
Dubinin-Radushkevich (DR) Isotherm Model: Making the linear plot according to adsorption capacity for the MB dye adsorption onto both adsorbents (UB and GMB) and the equilibrium concentrations, the DR adsorption isotherms (Figure 12) was obtained. Corresponding to which, the isotherm parameters were calculated as in Table 3 . The values of linear regression coefficient $\left(R^{2}\right)$ are in the range of 0.7908 and 0.9769 for $\mathrm{UB} / \mathrm{MB}$ and $\mathrm{GMB} / \mathrm{MB}$ respectively, revealing that the experimental data of $\mathrm{GMB} / \mathrm{MB}$ fitted well with the DR isotherm model than that of UB/MB. Moreover, Ibrahim and Sani (2014) reported that when the value of the mean free energy, $E$ is below $8 \mathrm{~kJ} / \mathrm{mol}$, the adsorption process can be considered as the physical adsorption. In contrast, if the value of $E$ is within the range of $8-16 \mathrm{~kJ} / \mathrm{mol}$, the adsorption processes is assumed to be chemical adsorption. From Table 3, it can be observed that the obtained values of $E$ for $\mathrm{UB} / \mathrm{MB}$ and $\mathrm{GMB} / \mathrm{MB}$ were within the range of 1.291 and $2.236 \mathrm{~kJ} / \mathrm{mol}$ respectively.

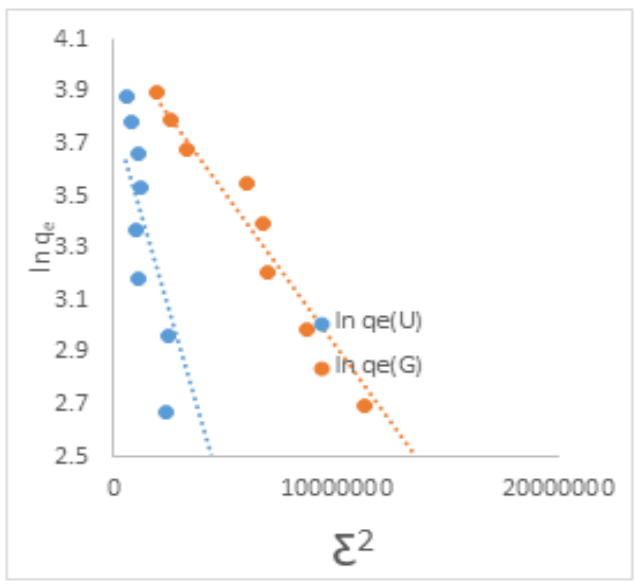

Fig 12: The linearized Dubinin-Radushkevich biosorption isotherm of MB on UB and GMB

Table 3: Parameters for the Langmuir, Freundlich, Temkin and D$\mathrm{R}$ adsorption isotherms for the uptake of MB onto UB and GMB.

\begin{tabular}{llll}
\hline Isotherms & Constants & UB & GMB \\
\hline Langmuir & $q_{\max }(\mathrm{mg} / \mathrm{g})$ & -1111.11 & -217.39 \\
& $K_{L}(\mathrm{~L} / \mathrm{mg})$ & -0.0138 & -0.1840 \\
& $R^{2}$ & 0.9293 & 0.9564 \\
& $R_{L}$ & $-2.6316-(1.3812)$ & $-0.0570-(-$ \\
Freundlich & $K_{F}(\mathrm{mg} / \mathrm{g})$ & 15.4253 & $0.3730)$ \\
& $R^{2}$ & 0.9026 & 43.1301 \\
& $n$ & 0.9240 & 0.9245 \\
Temkin & $K_{T}(\mathrm{~L} / \mathrm{mg})$ & 1.9373 & 1.0660 \\
& $R^{2}$ & 0.8148 & 5.7301 \\
D-R & $b_{T}$ & 1638.43 & 0.9691 \\
& $B_{D R}\left(\mathrm{~mol} / \mathrm{J}^{2}\right)$ & $3 \exp (-7)$ & 4325.19 \\
& $E(\mathrm{~kJ} / \mathrm{mol})$ & 1.291 & $1 \exp (-7)$ \\
& $q_{S}(\mathrm{mg} / \mathrm{g})$ & 43.9440 & 2.236 \\
& $R^{2}$ & 0.7908 & 60.4580 \\
\hline
\end{tabular}

Biosorption Kinetic Studies: Kinetic models are used to examine the rate of the biosorption process and 
determine the potential rate controlling step. In this present study, the kinetic data obtained from batch studies was analyzed using Pseudo-first order, Pseudosecond order, Elovich and Intra-particle diffusion models. The models predicted values are expressed by the regression equation, $\mathrm{R}^{2}$ and a high value indicates that the model successfully describes the biosorption process.

Pseudo-First order model: The plot of $\ln \left(q_{e}-q_{t}\right)$ against $t$ as shown in Figures 13 gave the slope of $K_{1}$ and intercept of $\ln q_{e}$. Table 4 shows the pseudo-first order constant values for adsorption of $\mathrm{MB}$ on $\mathrm{UB}$ and GMB. A low $\mathrm{R}^{2}$ value (not close to unity) indicates that the model does not sufficiently describe the kinetic data. Disparity between $q_{e}(\mathrm{mg} / \mathrm{g})$ calculated and $q_{e}(\mathrm{mg} / \mathrm{g})$ experimental further suggest that this model does not sufficiently describe the data.

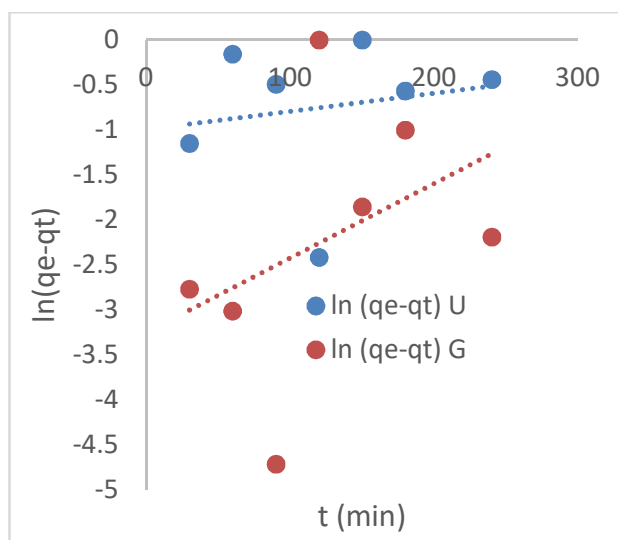

Fig 13: Pseudo-first order biosorption model of $\mathrm{MB}$ on UB and GMB

Pseudo-second order model: Pseudo-second order model assumes that the rate limiting step may be chemisorption involving valence forces through sharing or exchange of electrons between sorbent and sorbate (Aryal, 2011). This model is also based on the sorption equilibrium capacity. The values of Pseudosecond order plots are shown in Table 3. As shown in Figure 14 , the $\mathrm{MB}$ adsorption on $\mathrm{UB}$ has $\mathrm{R}^{2}$ value of 0.9968 and $q_{e}$ experimental of $9.8927 \mathrm{mg} / \mathrm{g}$ is almost the same as $q_{e}$ calculated $9.2937 \mathrm{mg} / \mathrm{g}$, it can be concluded that the kinetic model describes the kinetic data. For $\mathrm{MB}$ on $\mathrm{GMB}, \mathrm{R}^{2}$ value of 0.9993 was obtained and there was no significant difference between the $q_{e}$ experimental $(9.8927 \mathrm{mg} / \mathrm{g})$ and $q_{e}$ calculated $(9.6712 \mathrm{mg} / \mathrm{g})$, it can then be concluded that the biosorption process are best described by pseudosecond order model.

Elovich Model: One of the most used kinetic model for describing chemisorptions is Elovich model, it was originally developed to describe the kinetics of heterogeneous chemisorptions. Table 4 below shows the constant values obtained when the kinetic data were fitted into Elovich model. The plot of $q_{t}$ against $\ln t$ as shown in Figures 15 gave the slope of $1 / \beta$ and intercept of $\ln (\alpha \beta)$. A low $\mathrm{R}^{2}$ value (not close to unity) indicates that the model does not sufficiently describe the kinetic data. Disparity between $q_{e}(\mathrm{mg} / \mathrm{g})$ calculated and $q_{e}(\mathrm{mg} / \mathrm{g})$ experimental further suggest that this model does not sufficiently describe the data.

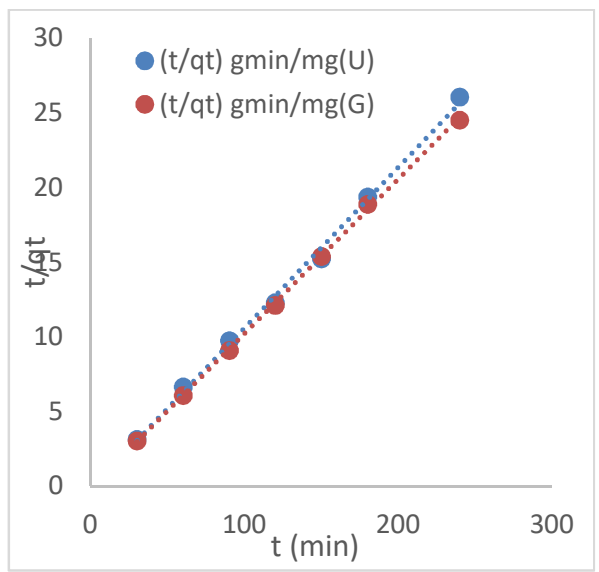

Fig 14: Pseudo-second order biosorption model of $\mathrm{MB}$ on $\mathrm{UB}$ and GMB

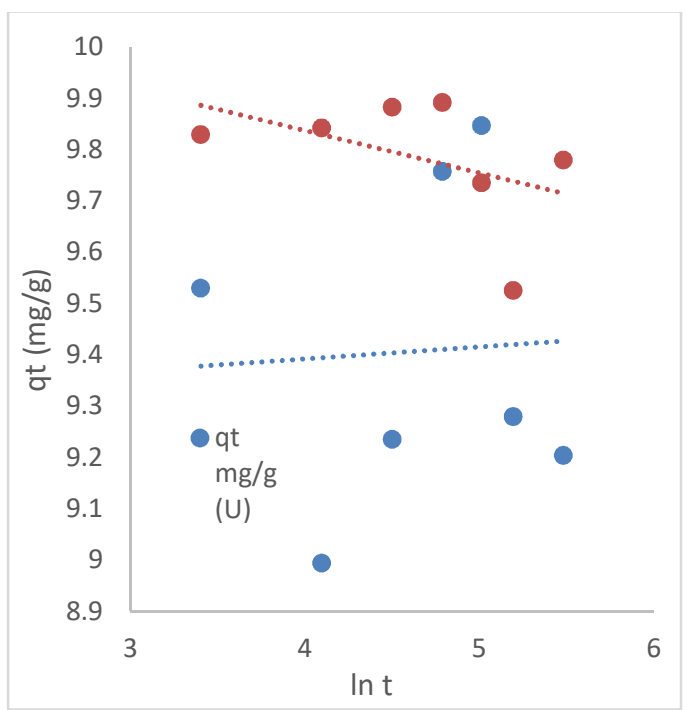

Fig 15: Elovich biosorption model of MB on UB and GMB

Intra-particle Diffusion model: This model is used to explain the diffusion mechanism of the sorption process. When the plot of $q_{t}$ versus $\mathrm{t}^{0.5}$ gives a straight line, the intra-particle diffusion controls the adsorbate sorption process. If it does not pass through the origin, 
the intra-particle diffusion is not the rate-limiting step (Aryal, 2011). Table 4 below shows the constant values obtained when the kinetic data were fitted into Intra-particle model and Figure 16 show the intraparticle diffusion model plots for the biosorption of CR and $\mathrm{MB}$ on the two adsorbents, the low correlation coefficient values obtained for this model indicate that the sorption is not occurring in the pores of biomass which suggests that the biosorption processes were not best described by the model.

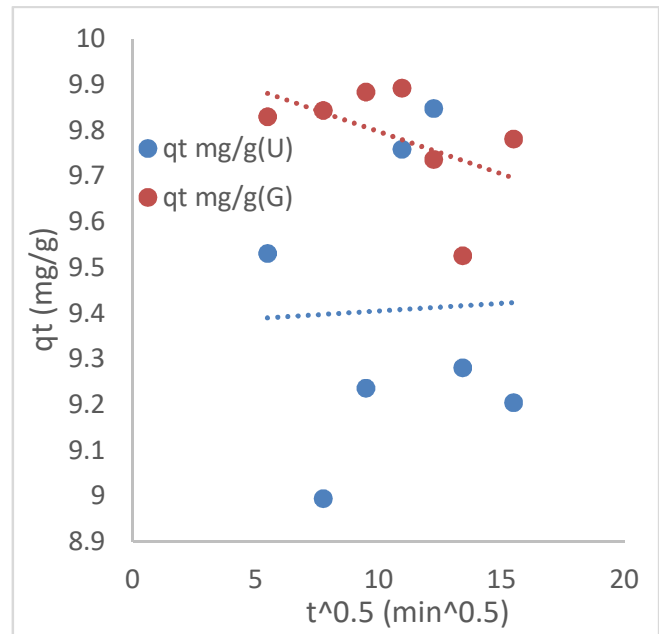

Fig 16: Intra-particle Diffusion Model for the biosorption model of $\mathrm{MB}$ on UB and GMB

Table 4: Comparison of pseudo-first-order, pseudo-second-order and intraparticle diffusion kinetics model parameters for the biosorption of MB onto UB and GMB

\begin{tabular}{lll}
\hline Parameters & UB & GMB \\
\hline$q_{e}$ Exp $(\mathrm{mg} / \mathrm{g})$ & 9.8928 & 9.8927 \\
\hline Pseudo-first order model & & \\
$q_{e}$ Calc $(\mathrm{mg} / \mathrm{g})$ & 0.3696 & 0.0388 \\
$R^{2}$ & 0.0313 & 0.1565 \\
$K_{1}$ & -0.002 & -0.0083 \\
\hline Pseudo-second order model & & \\
$q_{e}$ Calc $(\mathrm{mg} / \mathrm{g})$ & 9.2937 & 9.6712 \\
\multicolumn{1}{c}{$K_{2}$} & -0.0743 & -0.0993 \\
$R^{2}$ & 0.9968 & 0.9993 \\
\hline Elovich model & & \\
$\alpha$ (mg/g.min) & $2.7876 \times 10^{173}$ & $2.5681 \mathrm{X} 10^{54}$ \\
$\beta$ (g/mg) & 42.553 & -12.0773 \\
$R^{2}$ & 0.0028 & 0.2155 \\
\hline Intra-particle diffusion & \multicolumn{3}{|}{} \\
$k_{\text {id }}(\mathrm{g} / \mathrm{mg} / \mathrm{min})$ & 0.0034 & -0.0185 \\
$C$ (mg/g) & 9.3714 & 9.9824 \\
$R^{2}$ & 0.0014 & 0.2496 \\
\hline
\end{tabular}

The negative values of $\Delta \mathrm{G}$ for UB (Table 5) indicate a spontaneous physiosorption. The enthalpy changes $\Delta \mathrm{H}^{\circ}$ and $\Delta \mathrm{S}^{\circ}$ of adsorption for both samples were $83.123 \mathrm{KJ} / \mathrm{mol}$ and $3.084 \mathrm{~J} / \mathrm{mol} / \mathrm{K}$ for UB while $361.094 \mathrm{KJ} / \mathrm{mol}$ and $1.765 \mathrm{~J} / \mathrm{mol} / \mathrm{k}$ for $\mathrm{GMB}$ respectively. The positive values of $\Delta \mathrm{H}^{\circ}$ for both $\mathrm{UB}$ and GMB indicates that the adsorption of MB blue is an endothermic process. Positive values of entropy reflects the affinity of the adsorbent for Methylene Blue dye.

Table 5: Thermodynamic parameters for the biosorption of Methylene Blue on UB and GMB

\begin{tabular}{llll}
\hline \multicolumn{4}{c}{ Methylene Blue on UB and GMB } \\
\cline { 2 - 4 } & \multicolumn{3}{l}{ Thermodynamics } \\
\cline { 2 - 4 } & Parameters & UB & GMB \\
\cline { 2 - 4 } & $\Delta \mathrm{H}(\mathrm{KJ} / \mathrm{mol})$ & 83.123 & 361.094 \\
& $\Delta \mathrm{S}$ & 3.084 & 1.765 \\
& $\mathrm{R}^{2}$ & 0.171 & 0.934 \\
Temperature & $\Delta \mathrm{G}$ & & \\
27 & & -0.15 & 313.44 \\
30 & & -9.39 & 308.14 \\
35 & & -24.82 & 299.32 \\
40 & $\Delta \mathrm{G}$ & -40.24 & 290.49 \\
45 & & -55.66 & 281.67 \\
50 & & -71.08 & 272.84 \\
60 & & -101.92 & 255.19 \\
\hline
\end{tabular}

Conclusion: This study shows that optimum dye removal was at $\mathrm{pH} 10$ for both $\mathrm{UB}$ and GMB. The biosorption was satisfactorily described by the Langmuir isotherm. The adsorption process fits better into the pseudo-second-order kinetics for the adsorption of $\mathrm{MB}$ on both biosorbents. The adsorption was found to be spontaneous at all temperatures with negative $\Delta \mathrm{G}$ values. Also, the biosorption of Methylene Blue on both UB and GMB was found to be endothermic. Baobab fruit pod treated with goethite (GMB) can be used as a cheaper alternative to expensive activated charcoal to remove Methylene Blue.

\section{REFERENCES}

Abdus-Salam, N; Adekola, SK (2018). Adsorption studies of Zinc (II) on magnetite, baobab (Adansonia digitata) and magnetite-baobab composite. Applied water Science. 8:222

Adewuyi, A; Pereira, FV (2016). Nitrilotriacetic acid functionalized Adansonia digitata biosorbent: Preparation, characterization and sorption of $\mathrm{Pb}$ (II) and $\mathrm{Cu}$ (II) pollutants from aqueous solution. Journal of Advanced Research. 7: 947-959.

Akbal F (2005). Sorption of phenol and 4chlorophenol onto pumice treated with cationic surfactant. Journal of Environmental Management. 74(3): 239-244

Alam, MS; Khanom, R; Rahman, MA (2015). Removal of Congo red dye from industrial wastewater by untreated sawdust. American Journal of Environmental Protection. 4(5): 207213 
Allouche, F-N; Yassaa, N (2018). Potential adsorption of methylene blue from aqueous solution using green macro algae Posidonia oceanica. IOP Conference Series: Materials Science and Engineering. 323012006

Aryal, M; Liakopoulou-Kyriades, M (2011). Equilibrium, kinetics and thermodynamic studies on phosphate biosorption from aqueous solutions by $\mathrm{Fe}$ (III) treated Staphylococcus xylosus biomass: Common ion effect. Colloids and Surfaces A: Physicochemical and Engineering Aspects, 387 (1-3), 43- 49

Bulut, Y; Aydin, H (2006). A kinetics and thermodynamics study of methylene blue adsorption on wheat shells, Desalination 194, 259267

Bhatnagar, A; Jain, AK (2005). A comparative adsorption study with different industrial wastes as adsorbents for the removal of cationic dyes from water. Journal of Colloid and Interface Science, 281 (1), 49-55

Carvalho, WS; Martins, DF; Gomes, FR; Leite, IR; Gustavo da Silva, L; Ruggiero, R; Richter EM (2011). Phosphate adsorption on chemically modified sugarcane bagasse fibres. Biomass and Bioenergy 35 (9): 3913-3919.

Chien, SH; Clayton, W R (1955). Application of Elovich Equation to the Kinetics of Phosphate Release and Sorption in Soils. Soil Science Society of American Journal. 44, 265-268

Chigondo, F; Nyamunda, BC; Sithole, SC; Gwatidzo, L (2013). Removal of lead (II) and copper (II) ions from aqueous solution by baobab (Adansonia digitata) fruit shells biomass. IOSR Journal of Applied Chemistry. 5 (1): 43-50.

Crini, G; and Pierre-Marie, B (2008). Application of chitosan, a natural aminopolysaccharide, for dye removal from aqueous solutions by adsorption processes using batch studies: A review of recent literature. Progress in Polymer Science. 33 (4), 399-447

Dash, B (2010). Competitive Adsorption of dyes (Congo red, Methylene blue, Malachite green) on Activated Carbon. B. Tech Project, Department of Chemical Engineering National Institute of Technology, Rourkela Orissa -769 008, India. pp $1-31$
Deng, H; Yang, L; Tao, G; Dai, J (2009). Preparation and characterization of activated carbon from cotton stalk by microwave assisted chemical activation-Application in methylene blue adsorption from aqueous solution. Journal of Hazardous Materials. 166: 1514-1521

Dubinin, MM (1960). The potential theory of adsorption of gases and vapors for adsorbents with energetically non-uniform surface, Chemical Reviews 60 (2): 235-266

Eberhardt, TL; Min, SH; Han, JS (2006). Phosphate removal by refined aspen wood fiber treated with carboxymethyl cellulose and ferrous chloride. Bioresource Technology. 97 (18), 2371-2376

Etim, EU (2019). Removal of methylene blue dye from aqueous solution by adsorption unto groundnut waste. Biomedical Journal of Scientific and Technical Research, 15 (3): 11365 - 11371.

Frini A; El Maaoui, M (1997). Kinetics of the formation of goethite in the presence of sulfates and chlorides of monovalent cations. Journal of Colloid and Interface Science 190 (2), 269- 277

Gedam, VV; Raut, P; Chahande, A; Pathak, P (2019). Kinetic, thermodynamics and equilibrium studies on the removal of Congo red dye using activated teak leaf powder. Applied Water Science 9 (3): 55

Guiza, S; Ghiloufi, K; Bagane, FM (2014). Utilization of waste Tunisian palm tree date as low-cost adsorbent for the removal of dyes from textile wastewater. Mediterranean Journal of Chemistry, 3(5), 1044-1052.

Gupta, GS; Shukla, SP (1996). An inexpensive adsorption technique for the treatment of carpet effluents by low cost materials. Adsorption Science and Technology 13 (1), 15-26

Ho, YS; McKay, G (1998). Sorption of dye from aqueous solution by peat. Chemical Engineering Journal, 70 (2), 115-124

Ibrahim, MB; Sani, S (2014): Comparative isotherm studies on the removal of Congo red from wastewater by watermelon rinds and neem-tree leaves. Open Journal of Physical Chemistry. 4 (4): 139-146

Inyinbor, AA; Adekola, FA; Olatunji, GA (2015). EDTA modified Irvingia gabonensis: an efficient bioresource material for the removal of rhodamine 
B. Pakistan Journal of Analytical Environmental Chemistry. 16 (2): 38-47

Isık, M; Sponza, DT (2008). Anaerobic/aerobic treatment of a simulated textile wastewater. Separation and Purification Technology. 60 (1): 64-72

Jumasiah, A; Chuah, TG; Gimbon, J; Choong, TSY; Azni, I (2005). Adsorption of basic dye onto palm kernel shell activated carbon: Sorption equilibrium and kinetics studies. Desalination. 186(1-3): 57-64

Kannan, N; Sundaram, MM. (2001). Kinetics and mechanism of removal of methylene blue by adsorption on various carbons: A comparative study. Dyes and Pigments. 51(1), 25-40

Kargi, F; Ozmıhc1, S (2004). Biosorption performance of powdered activated sludge for removal of different dyestuffs. Enzyme and Microbial Technology. 35 (2-3): 267-271

Kaur, H; Thakur, A (2014). Adsorption of congo red dye from aqueous solution onto ash of Cassia fistula seeds: kinetic and thermodynamic studies. Chemical Science Review and letters. 3 (11S): 159169

Kini, MS; Saidutta, MB; Murty, VR (2014). Studies on biosorption of methylene blue from aqueous solutions by powdered palm tree flower (Borassus flabellifer). International Journal of Chemical Engineering.

2014 (http://dx.doi.org/10.1155/2014/306519) Article ID 306519: 13 pages

Kodzwa, JJ; Danha, C; Mangori, L; Chemura, A (2015). Activated carbon from baobab fruit shells through domestic processes. Zimbabwe Journal of Technological Sciences Special Issue (2nd International Research Conference: "Research, Technology and Innovation for Development in Africa” 20-21 July 2015):19-28

Kumar, DH; Harinath, Y; Seshaiah, K; Reddy, AVR (2010): Biosorption of $\mathrm{Pb}$ (II) from aqueous solutions using chemically modified Moringa oleifera tree leaves. Chemical Engineering Journal. 162 (2): 626-634

Kumaraswamy, K; Dhananjaneyulu, BV; Kumar, MSJ (2014). Adsorption studies of Congo red from aqueous solution on to rice husk. Research Journal of Pharmaceutical, Biological and Chemical Sciences. 5(1): 317-325
Langmuir, I. (1916). The constitution and fundamental properties of solids and liquids Part 1. Solids. Journal of the American Chemical Society 38 (11): 2221-2295

Low MJD (1960). Kinetics of chemisorption of gases on solids. Chemical Reviews, 60 (3): 267-312

McKay, G; Ramprasad, G; Mowli, PP (1986). Equilibrium studies for the adsorption of dyestuffs from aqueous solutions by low-cost materials. Water, Air, and Soil Pollution, 29 (3): 273-283

Michalak, I; Chojnacka, K; Witek-Krowiak, A (2013). State of the Art for the Biosorption Process: A Review. Applied Biochemistry and Biotechnology. 170 (6):1389-1416

Milani, A; Ciammella, A; Degen, C; Siciliano, M; Rossi, L (1992). Ascites dynamics in cirrhosis: Proposal and validation of a methylene blue dilution test. Journal of Hepatology. 16 (3): 369375

Misihairabgwi, JM; Kasiyamhuru, A; Anderson, P; Cunningham, CJ; Peshkur, TA; Ncube, I (2014). Adsorption of heavy metals by agroforestry waste derived carbons applied to aqueous solutions. African Journal of Biotechnology. 13(14): 15791587

Nirmala, S; Pasupathy, A; Raja, M (2016). Removal of Methylene Blue Dye From Aqueous Solution by Adsorption Using Low Cost Adsorbent Obtained from Centella Asiatica Leaves. International Journal of Scientific and Research Publications. 6 (12): 503-507

Ofudje, EA; Akiode, OK; Oladipo, GO; Adedapo, AE; Adebayo, LO; Awotula, AO (2015). Application of raw and alkaline-modified coconut shaft as a biosorbent for $\mathrm{Pb}^{2+}$ removal. BioResources. 10 (2):3462-3480

Padmesh, TVN; Vijayaraghavan, K; Anand, K; Velan, M (2008). Biosorption of basic dyes onto Azolla filiculoides: Equilibrium and kinetic modelling. Asia-Pacific Journal of Chemical Engineering. 3 (4): 368-373

Park, D; Yun, YS; Park, JM (2010). The past, present, and future trends of biosorption. Biotechnology and Bioprocess Engineering. 15(1): 86-102 
Raju, CAI; Kumari, SR; Satya, V; Rao, PJ; Bai, MT (2012). Biosorption performance of Albezia lebbeck pods powder for the removal of lead: Application of statistical method. International Journal of Modern Engineering Research. 2 (3): 1297- 1305

Rezaei, H (2016). Biosorption of chromium by using Spirulina sp. Arabian Journal of Chemistry 9 (6): 846-853

Tchikuala, E; Mourão, P; Nabais, J (2017). Valorisation of natural fibres from African baobab wastes by the production of activated carbons for adsorption of diuron. Procedia Engineering. 200: 399-407

Tempkin, MI; and Pyzhev, V (1940). Kinetics of ammonia synthesis on promoted iron catalyst. Acta Physiochim. URSS. 12: 327-356

Uddin, MT; Islam, MS; Abedin, MZ (2007). Adsorption of phenol from aqueous solution by water hyacinth ash. ARPN Journal of Engineering and Applied Sciences 2(2): 11-17

Unuabonah EI; Gunter, C; Weber, J; Lubahn, S; Taubert, A (2013). Hybrid clay: a new efficient adsorbent for water treatment. ACS Sustainable Chemistry and Engineering. 1 (8): 966-973

Vadivelan, V; Kumar, KV (2005). Equilibrium, kinetics, mechanism, and process design for the sorption of methylene blue onto rice husk, Journal of Colloid and Interface Science. 286 (1): 90-100

Vafakhah, S; Bahrololoom, ME; Bazarganlari, R; Saeedikhani, M (2014). Removal of copper ions from electroplating effluent solutions with native corn cob and corn stalk and chemically modified corn stalk. Journal of Environmental and Chemical Engineering. 2 (1): 356-361
Vučurović, VM; Razmovski, RN; Miljić, UD; Puškaš, VS (2014). Removal of cationic and anionic azo dyes from aqueous solutions by adsorption on maize stem tissue. Journal of the Taiwan Institute of Chemical Engineers. 45(4): 1700-1708

Vunain, E; Biswick, T (2019). Adsorptive removal of methylene blue from aqueous solution on activated carbon prepared from Malawian baobab fruit shell wastes: Equilibrium, kinetics and thermodynamic studies. Separation Science and Technology. 54 (1):27-41

Vunain, E; Kenneth, D; Biswick, T (2017). Synthesis and characterization of low-cost activated carbon prepared from Malawian baobab fruit shells by $\mathrm{H}_{3} \mathrm{PO}_{4}$ activation for removal of $\mathrm{Cu}$ (II) ions: equilibrium and kinetics studies. Applied Water Science. 7: 4301-4319

Weber, WJ; Morris, JC (1963). Kinetics of adsorption on carbon from solutions, Journal of the Sanitary Engineering Division. 89 (2), 31-60

Wong, YC; Szeto, YS; Cheung, WH; McKay, G (2004). Adsorption of acid dyes on chitosanequilibrium isotherm analyses. Process Biochemistry, 39(6):695-704

Xiong, JB; Mahmood, Q (2010). Adsorptive removal of phosphate from aqueous media by peat. Desalination, 259(1-3): 59-64 